\title{
CAMA
}

Centre for Applied Macroeconomic Analysis

\section{Impact of German Energiewende on Transmission Lines in the Central European Region}

\section{CAMA Working Paper 72/2017 November 2017}

\section{Jan Málek}

DIW, Berlin

\section{Lukáš Rečka}

Charles University, Prague

\section{Karel Janda}

Charles University, Prague

University of Economics, Prague

Centre for Applied Macroeconomic Analysis, ANU

\section{Abstract}

The impacts of renewable energy production and German nuclear phase-out on the electricity transmission systems in Central Europe is investigated with focus on the disparity between the growth of renewable production and the pace at which new electricity transmission lines have been built, especially in Germany. This imbalance endangers the system stability and reliability in the whole region. The assessment of these impacts on the transmission grid is analysed by the direct current load flow model ELMOD. Two scenarios for the year 2025 are evaluated from different perspectives. The distribution of loads in the grids is shown. Hourly patterns are analysed. Geographical decomposition is made, and problematic regions are identified. The high solar or wind power generation decrease the periods of very low transmission load and increase the mid- and high load on the transmission lines. High solar feed-in has less detrimental impacts on the transmission grid than high wind feed-in. High wind feed-in burdens the transmission lines in the north-south direction in Germany and water-pump-storage areas in Austria. 


\section{Keywords}

Energiewende, RES, transmission networks, congestion, loop flows, ELMOD, Central Europe

\section{JEL Classification}

L94, Q21, Q48, C61

Address for correspondence:

(E) cama.admin@anu.edu.au

ISSN 2206-0332

The Centre for Applied Macroeconomic Analysis in the Crawford School of Public Policy has been established to build strong links between professional macroeconomists. It provides a forum for quality macroeconomic research and discussion of policy issues between academia, government and the private sector.

The Crawford School of Public Policy is the Australian National University's public policy school, serving and influencing Australia, Asia and the Pacific through advanced policy research, graduate and executive education, and policy impact. 


\title{
Impact of German Energiewende on Transmission Lines in the Central European Region*
}

\author{
Jan Málek ${ }^{\mathrm{a}}$, Lukáš Rečkab ${ }^{\mathrm{b}}$, and Karel Jandab,c,d \\ ${ }^{a}$ DIW, Berlin \\ ${ }^{\mathrm{b}}$ Charles University, Prague \\ ${ }^{\mathrm{c}}$ University of Economics, Prague \\ ${ }^{\mathrm{d} C e n t r e ~ f o r ~ A p p l i e d ~ M a c r o e c o n o m i c s ~ A n a l y s i s, ~ A u s t r a l i a n ~}$ \\ National University, Canberra
}

October 17, 2017

\begin{abstract}
The impacts of renewable energy production and German nuclear phase-out on the electricity transmission systems in Central Europe is investigated with focus on the disparity between the growth of renewable production and the pace at which new electricity transmission lines have been built, especially in Germany. This imbalance endangers the system stability and reliability in the whole region. The assessment of these impacts on the transmission grid is analysed by the direct current load flow model ELMOD. Two scenarios for the year 2025 are evaluated from different perspectives. The distribution of loads in the grids is shown. Hourly patterns are analysed. Geographical decomposition is made, and problematic regions are identified. The high solar or wind power generation decrease the periods of very low transmission load and increase the mid- and high load on the transmission lines. High solar feed-in has less detrimental impacts on the transmission grid than high wind feed-in. High wind feed-in burdens the transmission lines in the north-south direction in Germany and water-pump-storage areas in Austria.
\end{abstract}

\author{
JEL Classification L94, Q21, Q48, C61 \\ Keywords Energiewende, RES, transmission networks, congestion, \\ loop flows, ELMOD, Central Europe
}

*Email addresses: janmalek.jm@gmail.com (Jan Málek), lukas.recka@czp.cuni.cz (Lukáš Rečka), Karel-Janda@seznam.cz (Karel Janda). This article is part of a project that has received funding from the European Union's Horizon 2020 research and innovation programme under the Marie Sklodowska-Curie grant agreement No. 681228. The authors further acknowledge support from the Czech Science Foundation (grants number 16-00027S and 15-00036S), the Technology Agency of the Czech Republic grant number TD03000319, Grant Agency of Charles University grant number 829317 and the University of Economic, Prague (institutional support IP100040). Karel Janda acknowledges research support provided during his long-term visits at McGill University and Australian National University. We would like to express sincerest thanks to the company GAMS Software, GmbH which granted Jan Malek a research licence for solving the model. 


\section{Introduction}

German governments have accepted an energy policy that supports the development of renewable energies, the reduction of greenhouse gas emissions, the improvement of energy efficiency and the phase out of nuclear power ('Energiewende'). As a result, generation from variable renewable energy sources (VRES) in Germany has experienced a considerable uptake in recent years (mainly due to the German Renewable Energy Sources Act (Erneuerbare Energien Gesetz, EEG)) which has led not only to lower electricity spot market prices but also to many challenges for the stability and security of electricity supply (Fischer et al. 2016). As Germany is the largest economy in the EU and represents the majority of wind and solar power generation in the Central Europe (CE) (80\% and 90\% of wind and solar power generation in CE in 2014, respectively), its energy policy influences energy systems in neighbouring countries not only in terms of power market prices (Mulder \& Scholtens 2016) but also in terms of stability, congestion and volatility of transmission grid (Janda et al. (2017); Kunz \& Zerrahn (2015)).

German centres of electricity consumption are situated mostly in the south and west but regions suitable for most economic VRES production are located in the north. The electricity generated by VRES must therefore be transported over long distances to the end-consumers in the north-south direction. As a result, the existing network is frequently reaching its capacity limits (Bundesnetzagentur 2015). The planned German phase-out of $8386 \mathrm{MW}$ of installed nuclear capacity by 2022 furthermore contributes to the north-south grid pressures since nuclear power plants are mostly located in southern regions, Bavaria and BadenWurttemberg. The loss of nuclear capacity is not expected to be fully offset by new installed capacities, which is the result of limited RES potential in the area (Flechter \& Bolay 2015). This embodies even larger pressure on the transmission grid and a need to strengthen the infrastructure in German north-south direction, as confirmed by German authorities (BMWi 2015a) and especially neighbouring transmission system operators (TSO) as described bellow. The grid expansion 
agenda is backed by two German laws - Power Grid Expansion Act (EnLAG) from 2009 and Federal Requirements Plan Act (BBPlG) from 2013.

The grid expansion proceeds slower than expected, since the volume of the infrastructure extension as well as the realization itself seem to be a matter of controversy. EnLAG legislature specified 23 mostly north-south transmission lines with the cumulative length of $1876 \mathrm{~km}$ that need to be urgently built to preserve the stability of the system in the environment of increasing RES production. The construction should have been finished by the end of 2015 (Flechter \& Bolay 2015). Nonetheless, in the first quarter of 2017, 35 kilometres of lines were built which gives around $700 \mathrm{~km}$ with previous construction (40\% of planned length). Estimates now calculate with $45 \%$ being built till the end of 2017 (Bundesnetzagentur 2017). BBPlG, which came into effect in July 2013, added another 43 planned extension lines out of which 16 are considered of cross-regional or cross-border importance. Corridors of future networks are now determined and a public discussion about the exact tracing is in progress (BMWi 2015c). As of first quarter of 2017, $14 \mathrm{~km}$ were built. Together with previous construction, 150 $\mathrm{km}$ of lines were realized and $450 \mathrm{~km}$ were approved (Bundesnetzagentur 2017). Mainly EnLAG activities suffer major project delays which can be ascribed to the negative public opinion and resistance which accompanies the network construction. The general public refuses the grid construction in the vicinity of their places of living and requires mostly the underground cable solutions. This is estimated to be up to 5 times more expensive than ordinary lines since a kilometre of line costs 1.2 Mio EUR whilst a kilometre of cable costs 6 Mio EUR (Rapp 2012). As a result, it is implausible that fast short term improvement with the $45 \%$ target is foreseeable.

The Czech TSO installed two phase-shifting transformers at one of the two CEPS - 50 Hertz interconnectors to manage the overflows from Germany in January 2017 and another two at the second interconnector in July 2017 with an approximate total cost of 74 mil EUR (ČEPS 2015a; 2017). The total volume 
of investments during current Czech development plan is estimated to reach 1.66 bn EUR by 2024 (ČEPS 2015b). Austrian and Polish development plans assume investment of 2.4 and 3 bn EUR by 2025, respectively (APG 2015; PSE 2015).

Existing literature extensively focused on the influence of VRES on spot and forward market prices of electricity (Traber \& Kemfert (2009); Cludius et al. (2014); Ketterer (2014); Meyer \& Luther (2004)), public budgets and consumer prices (Janda et al. (2014); Průša et al. (2013)) or power system in general (Blesl et al. (2007); Havlíčková et al. (2011); Rečka \& Ščasný (2016; 2013); Ščasný et al. (2009)). However much less attention has been drawn to transmission networks issues that are connected to the security of electricity supply and become increasingly crucial as the share of VRES rises. The majority of the transmission networks related research is focused only on Germany (Burstedde 2012; Kunz 2013; Kunz \& Zerrahn 2015; Schroeder et al. 2013; Egerer et al. 2014; Weigt et al. 2010; Dietrich et al. 2010; Winkler et al. 2016; Singh et al. 2015) or Europe as a whole (Neuhoff et al. 2013; Fürsch et al. 2013; Majchrzak et al. 2013; Schaber et al. 2012a;b). Polish researches examine mainly the possibilities of phase-shifting transformers on German cross-border profiles (Korab \& Owczarek 2016; Kocot et al. 2013).

There are only a few papers paying attention to the region of Central Europe (CE: Austria, Czech Republic, Germany, Poland and Slovakia). Singh et al. (2016) assess the impact of unplanned power flows on transmission networks. Eser et al. (2015) analyse the impact of increased renewable penetration under network development. Kunz \& Zerrahn (2016) focus on cross-border congestion management. Finally, Janda et al. (2017) analyse the impacts of increased renewable generation and nuclear phase-out in Germany on border-crossing profiles in the Czech Republic and other CE countries.

This paper fills the gap in the literature and contributes to the analysis of the impact of increasing wind and solar power generation and nuclear phase-out in the region of Central Europe (CE). Unlike other papers, we focus on the whole 
CE at the same level of detail as Germany and analyse the impacts of increased German VRES feed-in and nuclear phase-out on hourly grid load and volatility in transmission networks. Since Janda et al. (2017) focus on the cross-border profiles only, we assess here the impact on individual transmission lines in the CE region. We use the non-linear optimization model ELMOD (Leuthold et al. 2008), which maximizes social welfare under a number of constraints. We use a "critical scenario approach". This means that the results must be interpreted in the context of what would be the impact of electricity flows on the grid if nothing was changed in the grid development.

The rest of this paper is structured in the following way: Section 2 explains the ELMOD model and the following section 3 describes the data. Section 4 introduces our base scenario and two development policy scenarios, section 5 presents and interprets the results. The last section 6 concludes.

\section{Model}

This study applies the state-of-the-art DC load flow model ELMOD also used in Leuthold et al. (2012), Egerer et al. (2014) and Janda et al. (2017). The mathematical formulation can be found in the Appendix and is based on an optimization problem that maximizes social welfare after taking the technical and physical characteristics of electricity into account. The model looks for a solution that satisfies a given electricity demand at the least cost. The hourly resolution of demand load allows the merit order of the power sources. The modelling of physical flows of power enables that the final solution takes into account constraints of the grid and does not jeopardize its stability. This is the main advantage compared to models that do not include load flow modelling like MARKAL or TIMES model and that could reach a solution that could overload the grid dangerously. The maximization problem is solved for the whole area at once which is equivalent to the assumption of one TSO operating entire area. 
Electricity inputs include total generation from conventional power plants $\sum_{c} g_{n c t}$, wind generation $G_{n t}^{\text {wind }}$, solar generation $G_{n t}^{\text {solar }}$ and pumped-storage power plant release $P S P_{n t}^{\text {out }}$. The outputs include pumping of pumped-storage power plants $P S P_{n t}^{i n}$ and consumption (demand) $q_{n t}$.

The demand enters in hourly intervals as an external parameter as it is based on the real data. Thus, it can be considered as fixed for every node in every hour. Consequently, price adjusts to clear the demand and supply.

The model is merit-order based which implies that the plants with the cheapest production supply electricity first. However, the production from solar and wind plants has an absolute priority as it enters the model as an exogeneous parameter (see section 3). This set-up of the model therefore resembles reality very closely.

The flows over particular line in a given time period are modelled (eq. 5 in the appendix) and the phase angle for an arbitrary slack node is set to zero (eq. 7 in the appendix) to ensure the uniqueness of solutions (Egerer et al. 2014).

The ELMOD model uses a simplification of AC load flow to DC load flow model. Overbye et al. (2004) discusses the actual differences between the AC and DC flow applications and concludes that the loss of accuracy is small and that DC results match well AC load flow solutions. To simplify the flow calculations, ELMOD follows the work of Schweppe et al. (1988) and Stigler \& Todem (2005) where reactive power flows and transmission lines losses are neglected, angle differences are assumed to be small and voltages are standardized to per unit levels (see Purchala et al. (2005) for applicability of these assumptions).

As a result, DC load flow deals only with two variables - voltage angle and active power injections (eq. 8). The net input into a DC line is determined by the line flows of the DC lines multiplied by their factor in the incidence matrix. 


\section{Data description}

We use the same dataset as in Janda et al. (2017). It is based on Egerer et al. (2014) with several adjustments and updates. The transmission network system, power plant units and their technical characteristics are taken from Egerer et al. (2014) and resemble thus the state of the year 2012. Similarly to the application of Kunz \& Zerrahn (2016), the rest of the dataset related to electricity is updated to 2015. Hourly data for load, solar, wind, pump-storage plant generation and pump-storage plant pumping are obtained from the ENTSOE Transparency platform (ENTSOE 2016) or from the pages of individual TSOs in case of unavailability in the Transparency platform. Prices of electricity to calculate demand are obtained from European Commission, DG Energy (2016b). Power plant fuels prices are collected from several resources as shown in the table 1. Prices of $\mathrm{CO}_{2}$ allowances are retrieved from the database of European Energy Exchange (EEX) in Leipzig. Data on cross-country price differences in gas and oil are collected from European Commission, DG Energy (2016c) and European Commission, DG Energy (2016a), respectively.

The underlying grid data consist of nodes (transformer stations) which are connected by transmission lines. Our dataset consists of 593 nodes, 10 countryspecific nodes and 982 lines. Each transmission line is characterized by several parameters necessary to run a DC load flow model - number of circuits, length, resistance, reactance, voltage level and thermal limit.

There are two levels of detail in our data. First, the transmission systems of the CE countries are reflected to a most possible level of detail. This means structural nature of the network is modelled by taking into account actual lines and substations which are operated by the TSOs. The exact form of the transmission system can be found in Egerer et al. (2014, p.56). The second level is more aggregate. Following Leuthold (2009), adjacent countries (all states with interconnections to the CE region: Netherlands, Luxembourg, France, Switzerland, Italy, Slovenia, Hungary, Denmark, Sweden) are represented by country-specific 
single nodes which are interconnected with the CE region as well as between each other.

This distinguishes our paper and Janda et al. (2017) from most of other research that focus primarily on Germany and model only German network in such a detail. Another benefit is that incorporating aggregated neighbouring countries as nodal entities prevents the occurrence of severe biases in resulting flows which would be the consequence of absent transit and loop flows of electricity between $\mathrm{CE}$ and adjacent areas.

The transmission grid has to fulfil the "N-1" security criterion which is a basic criterion of power system stability. It requires that the system is able to operate and supply electricity provided a sudden outage of one system element occurs (Neuhoff et al. 2005). In the model, this security constraint is introduced by a $20 \%$ reliability margin in the thermal limit of each line (Leuthold et al. 2008, p.13).

The 607 power generation units in the $\mathrm{CE}$ region are assigned to specific nodes by the method of shortest distance. In the remaining single node countries, all generation units are summed up over the production technology and allocated to a respective single nodes. Due to the data availability issues, all power plants data are taken from Egerer et al. (2014). The limitation of this approach is that the generation capacities reflects the state in the year 2012. Thus an assumption about time-invariant development of generation capacities had to be made for the years 2013 to 2015 . The only exception is the German nuclear phase-out which is fully reflected in the dataset in the case of phase-out scenario.

Actual generation from individual plants is subject to model optimization after taking technical parameters of the plants into account. These include fuel cost, generation efficiency and availability of production units. Fuel and emission prices have to be introduced as these represent the short-term variable costs of producing one MWh. This applies to conventional power plants whereas RES are considered at the zero production cost. For both types, operation and maintenance costs 
as well as unit commitment costs are not considered (Egerer et al. 2014). Input prices of fuels are given in the table 1 together with the respective data sources. All prices are updated to 2015 values except the price of coal for which only 2014 values are available.

Tab. 1: Fuel prices

\begin{tabular}{lcll}
\hline Fuel & Price & Unit & Source \\
\hline \hline Uranium & 3 & EUR/MWh & Assumption of Egerer et al. (2014) \\
Lignite & 3.48 & EUR/MWh & Own calculation \\
Hard Coal & 6.96 & EUR/MWh & BP: Northwestern Europe coal price 2014 \\
Gas & 22.28 & EUR/MWh & EC: Quarterly reports on European gas markets \\
Oil & 28.42 & EUR/MWh & Bloomberg: Brent oil price \\
Biomass & 7.2 & EUR/MWh & Assumption of Egerer et al. (2014) \\
Hydro & 0 & EUR/MWh & \\
Wind & 0 & EUR/MWh & \\
Sun & 0 & EUR/MWh & \\
Waste & 7.2 & EUR/MWh & Assumption of Egerer et al. (2014) \\
Carbon & 7.59 & EUR/tCO & EEX: Median $\mathrm{CO}_{2}$ EUA settlement prices \\
\hline
\end{tabular}

ENTSOE database is the national level source of hourly load data for all included countries for the year 2015. National level values are disaggregated to NUTS2 level according to Egerer et al. (2014) and Leuthold et al. (2012) (GDP $60 \%$ weight, population $40 \%)$.

Secondary utilization of the load data occurs in the optimization problem where the welfare function is maximized. At each node, reference demand, reference price and elasticity are estimated in order to identify demand via a linear demand function (Leuthold et al. 2012). For a more detailed description of the data see Janda et al. (2017).

Similarly to Schroeder et al. (2013) and Janda et al. (2017) three representative weeks with the different combinations of extreme values of RES production are used and investigated in detail (we use English-type weeks, i.e. the week starts on Sunday). In contrast to Janda et al. (2017), who analyse week 4 and week 14, we focus on week 14 (last week in March - from 29th March to 4th April, 2015) when the highest cumulative production from wind and sun occurs in CE; 
week 27 (last week in June from 28th June to 4th July, 2015); and week 49 (last week in November from 29th November to 5th December, 2015). This allows to capture the effects of individual VRES. Week 27 represents the situation when the solar feed-in is high and wind feed-in is low. Week 49 mirrors exactly the opposite. Figures 1-3 depict the situation during each of the considered weeks.

\section{Scenarios}

To measure the influence of the increased installed capacity of VRES over time and space, electricity flows over the individual lines within the network are obtained for each hour of the week. The results are then compared in the context of three scenarios: base, res-only and phase-out.

The base is our reference scenario that models the current situation in the power sector in CE based on data specified in section 3 .

Scenario phase-out assesses the impacts of increase of VRES production in Germany and German nuclear phase-out in CE context. It is derived from the base scenario by taking into account the aims of German energy policy for the year 2025. Parameters reflecting the VRES production are multiplied by appropriate coefficients (table 2) and nuclear power plants are phased-out. Everything else in Germany as well as in the other countries, including grids, reflects the state of 2015 or other years as specified in the section 3. By construction, the results must be interpreted in the context of the worst possible outcome if nothing is done in network development.

All relevant electricity-related Energiewende goals are defined as a percentage of electricity consumption as compared to the year 2008. According to AGEB (2015), 618.2 TWh of electricity was consumed in Germany in 2008. Energiewende goals require the electricity consumption to be reduced by $10 \%$ until 2020 and by 25\% until 2050 (BMWi 2015b). Linear approximation leads to $12.5 \%$ reduction in 2025 which accounts for 541 TWh. This is equivalent to $90.61 \%$ of 
Fig. 1: High wind and high solar production profile (Week 14)

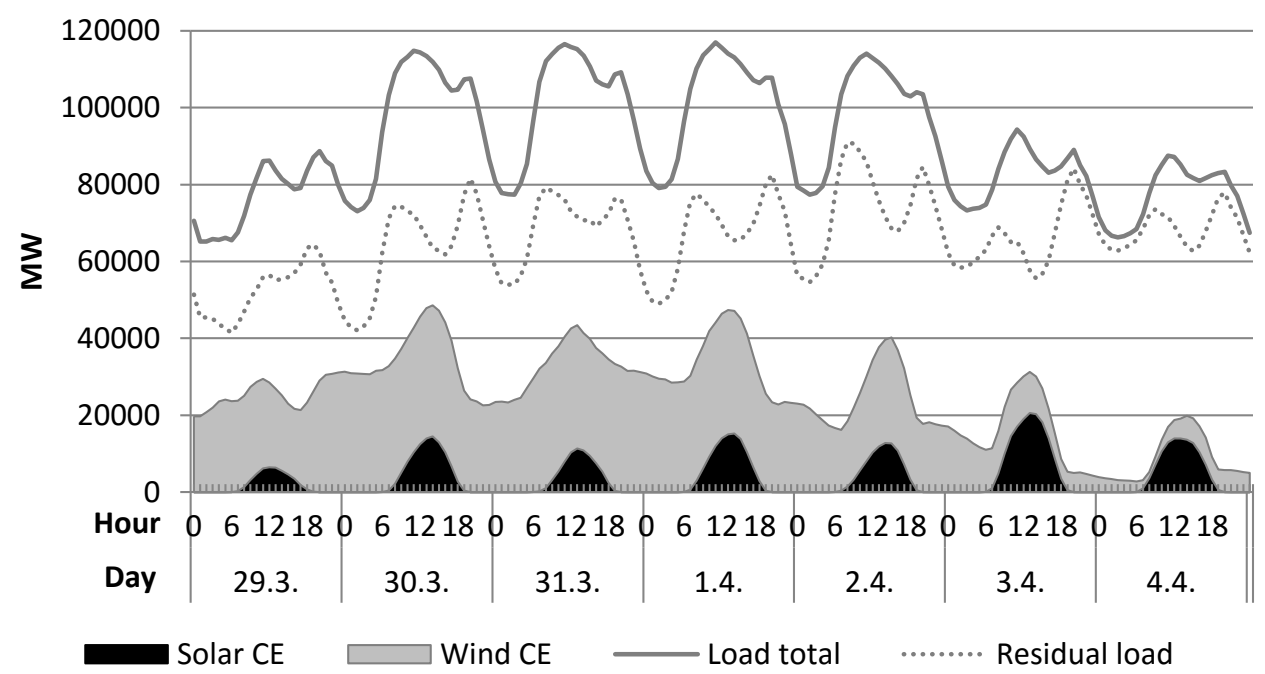

Fig. 2: Low wind and high solar production profile (Week 27)

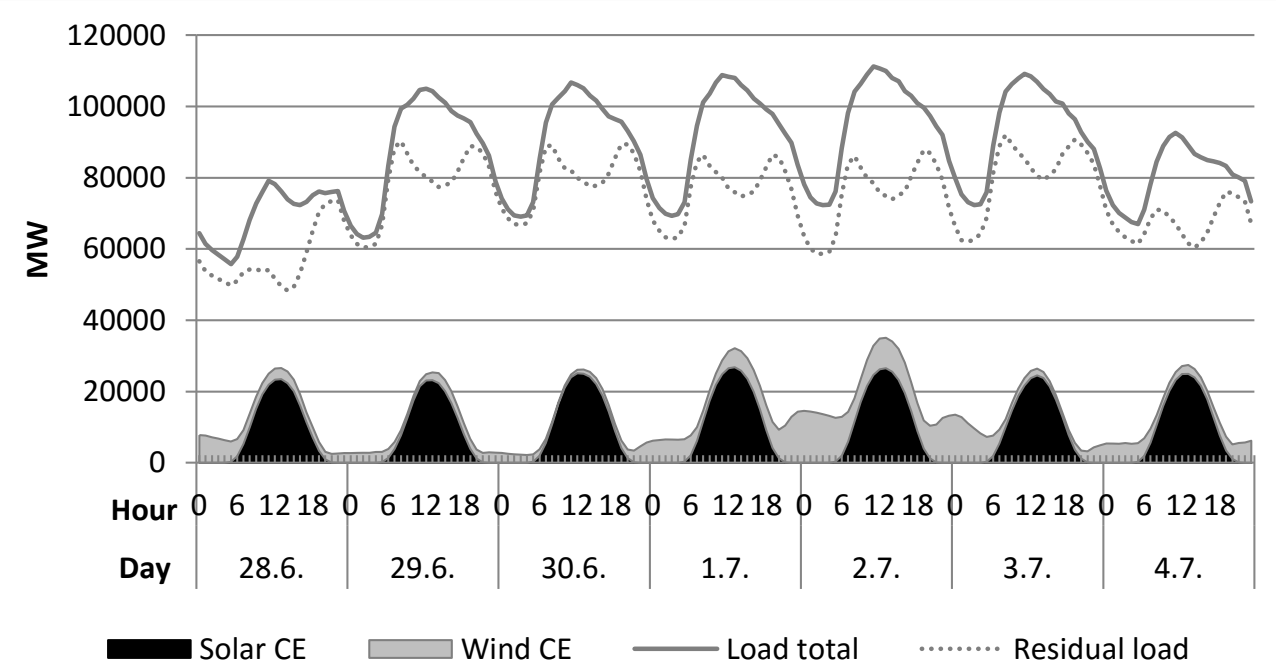

Fig. 3: High wind and low solar production profile (Week 49)

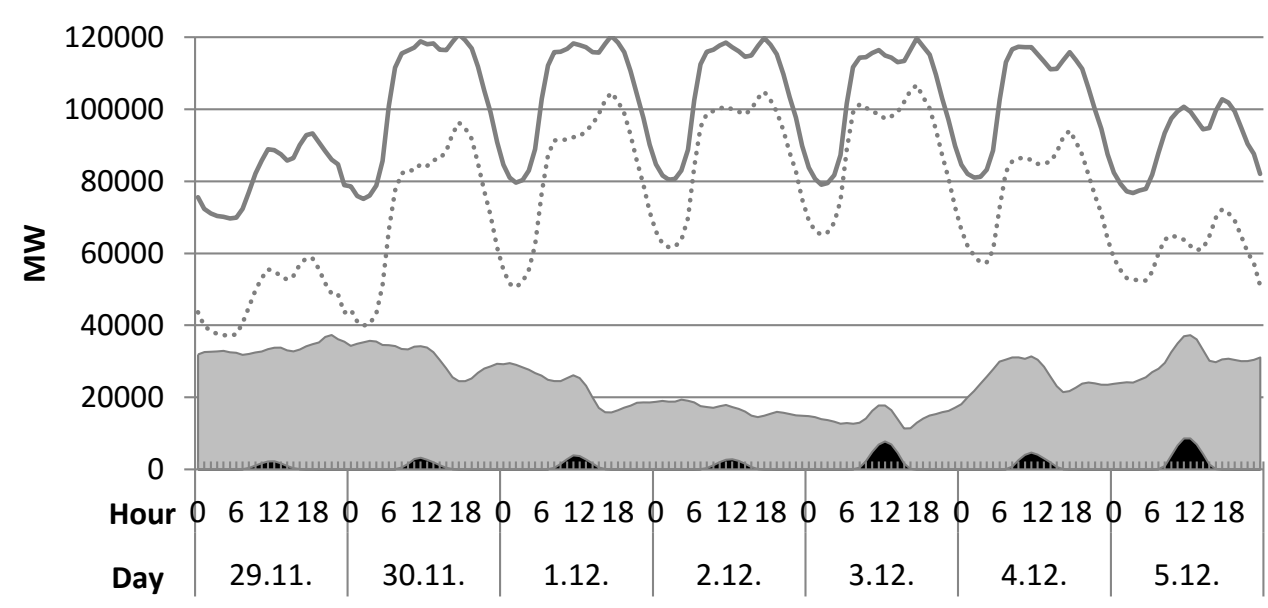

$\square$ Solar CE $\square$ Wind CE $\longrightarrow$ Load total $\quad \ldots . . .$. Residual load 
the 2015 consumption.

Shares of solar and wind electricity generation are based on the scenario "2025 A" from "Netzentwicklungsplan" (Feix et al. 2015) where installed capacities are projected. Actual generation is obtained by multiplying these figures by utilization factors of individual power plant types extracted from AGEB data. This approach yields the renewable/consumption ratio of $45.91 \%$, close to $42.5 \%$ which is the result of linear approximation for year 2025 using BMWi scenarios (BMWi 2015b). The derivations are shown in the table 2 .

Tab. 2: Parameters of phase-out scenario model

\begin{tabular}{|c|c|c|c|c|c|c|c|}
\hline TYPE & $\begin{array}{c}\text { Installed capacity } \\
2013 \text { (MW) } \\
\text { (1) }\end{array}$ & $\begin{array}{l}\text { Development } \\
\text { coefficient } \\
(2)\end{array}$ & $\begin{array}{c}\text { Installed capacity } \\
2025 \text { (MW) } \\
\text { (3) }\end{array}$ & $\begin{array}{l}\text { Full load } \\
\text { hours } \\
(4)\end{array}$ & $\begin{array}{c}\text { Generation } \\
2025(\mathrm{TWh}) \\
(5)\end{array}$ & $\begin{array}{l}\text { Generation } \\
2015 \text { TWh } \\
\quad(6)\end{array}$ & $\begin{array}{l}\text { Generation } \\
\text { coefficient } \\
\quad(7)\end{array}$ \\
\hline Solar & 36340 & 1.490 & 54159.61 & 969.77 & 52.52 & 38.50 & 1.364 \\
\hline Wind onshore & 33310 & 1.568 & 52231.66 & 1900.46 & 99.26 & & \\
\hline Wind offshore & 620 & 14.355 & 8900.00 & 3118.28 & 27.75 & & \\
\hline Wind & 33930 & & 61131.66 & & 127.02 & 86.00 & 1.477 \\
\hline Source: & Feix et al. (2015) & Feix et al. (2015) & $(1) *(2)$ & data BMWi (2015b) & $(3) *(4)$ & AGEB (2015) & $(5) /(6)$ \\
\hline
\end{tabular}

Values given in the column "Generation coefficients" are then that ones, by which original data for wind and solar production are multiplied. Finally, the BMWi scenario was selected because it is very likely that policy makers will stick to it and will therefore follow time-consistent development based on this scenario. This surmise is based on two pieces of evidence: first, the BMWi scenario exhibits extraordinarily high social acceptance when compared to other development scenarios (Schubert et al. 2015b), and, second, it focuses highly on economic viability and emission reduction (up to $80 \%$ as of 1990 (Keles et al. 2011)) which are both factors playing major role in German public's opinion on Energiewende (Schubert et al. 2015a).

Scenario res-only considers the same set-up as in the phase-out case with the exception of German nuclear power plants which are considered to be still in operation even after the planned shut down in 2022. This allows us to isolate the impact of shutting down the nuclear power plants on the grid by comparing the phase-out and res-only scenarios. 


\section{Results}

The results are presented for each of the mentioned weeks so that the different situations can be easily distinguished. Moreover, we first present the aggregate impacts and then focus on time and geographic dimensions separately.

\subsection{Impact of renewables and nuclear phase-out on transmis- sion lines congestion}

Table 3 depicts the distributions of 'load' of transmission lines in all representative weeks in the scenario base and percentage changes from the base in scenarios res-only and phase-out. The inputs in the table are "number of observations in given interval of the line 'load' ". These individual observations of load values are independent of line mapping. For example, first column and first line in the table 3 tell us that there were 94472 observations in the lowest 'load' decile in the week 14 in base scenario. By this approach, we assess the impact of the above mentioned scenarios on the distribution of system load within the particular week as a whole. The ex-ante hypotheses are that when renewable inflow increases then the distribution should be shift towards the high-'load' values as we expect more congestion in the network.

Both res-only and phase-out scenarios are associated with a decline in the number of observations in the lowest 'load' decile from 4 to 7 percent as compared to base in all three representative weeks. The second and third 'load' deciles differ across the weeks in term of direction of impact of res-only and phase-out scenarios. In week 14, with high solar and wind generation the number of observations (lines and hours) in the second 'load' decile remains of the same level as in scenario base in both alternative scenarios. However, there are 4 and 5 percentage increases in the res-only and phase-out scenarios in the third 'load' decile, respectively. Both the res-only and phase-out scenarios induce increase of observations in the fourth and higher 'load' deciles by 9 to 41 percent. Since summer week 27 with 
Tab. 3: Load distribution in scenario base and percentage difference of scenario res only and phase-out

\begin{tabular}{|c|c|c|c|c|c|c|c|c|c|}
\hline \multirow[b]{2}{*}{ Load [\%] } & \multicolumn{3}{|c|}{ w14 - high sun and wind } & \multicolumn{3}{|c|}{ w27 - high sun and low wind } & \multicolumn{3}{|c|}{ w47 - low sun and high wind } \\
\hline & $\begin{array}{r}\text { base } \\
\text { [obs.] }\end{array}$ & $\begin{array}{r}\text { res-only } \\
{[\% \text { change }]}\end{array}$ & $\begin{array}{l}\text { phase-out } \\
{[\% \text { change] }}\end{array}$ & $\begin{array}{r}\text { base } \\
\text { [obs.] }\end{array}$ & $\begin{array}{r}\text { res-only } \\
{[\% \text { change }]}\end{array}$ & $\begin{array}{l}\text { phase-out } \\
{[\% \text { change] }}\end{array}$ & $\begin{array}{r}\text { base } \\
\text { [obs.] }\end{array}$ & $\begin{array}{r}\text { res-only } \\
{[\% \text { change }]}\end{array}$ & $\begin{array}{l}\text { phase-out } \\
{[\% \text { change] }}\end{array}$ \\
\hline $0-10$ & 94472 & -4.5 & -4.7 & 117121 & -4.9 & -7.1 & "90679 & -4.7 & -3.9 \\
\hline $11-20$ & 30703 & -0.3 & 0.3 & 24008 & 6.9 & 13.1 & 33496 & -1.6 & -1.7 \\
\hline $21-30$ & 16540 & 3.6 & 5.0 & 10815 & 11.9 & 17.4 & 18813 & 0.0 & -1.2 \\
\hline $31-40$ & 10466 & 9.5 & 8.9 & 6212 & 11.7 & 15.6 & 10482 & 19.2 & 17.5 \\
\hline $41-50$ & 4917 & 20.4 & 20.5 & 3262 & 28.4 & 29.5 & 4749 & 19.7 & 18.6 \\
\hline $51-60$ & 2999 & 23.7 & 21.2 & 1573 & 31.0 & 41.1 & 2976 & 20.2 & 16.0 \\
\hline $61-70$ & 1602 & 36.2 & 32.5 & 813 & 34.9 & 29.4 & 1565 & 38.1 & 37.6 \\
\hline $71-80$ & 2295 & 21.8 & 19.3 & 1172 & 33.5 & 39.0 & 2216 & 27.6 & 26.0 \\
\hline 80 & 1529 & 21.5 & 19.8 & 833 & 32.8 & 36.4 & 1432 & 27.0 & 26.2 \\
\hline
\end{tabular}

NOTE: The 'load' is defined as a ratio of a flow over particular line in every hour and the capacity of the line, multiplied by 100. The inputs are hourly flows over each of the 982 model lines and capacities of the lines. There are 163994 observations for the week 14 (982 lines times 167 hours) and 164976 observations for the weeks 27 and 49 (982 lines times 168 hours) in each particular scenario. It is noteworthy that the highest values of the load is $80 \%$ as this embodies the highest admissible value because of the 'N-1' criterion. The 'load' measure is introduced to enable the mutual comparison of the results as the absolute value of the flow does not reflect different capacities of the lines.

high solar and low wind generation has the lowest grid load, the relative increase of observations in fifth to seventh 'load' decile is the highest in this week but the absolute 'load' of transmission lines is the lowest in res-only and phase-out scenarios in this week.

The last line in table 3 depicts observations of the $80 \%$ 'load' of transmission lines when the load encounters the model constraint reflecting the N-1 rule and the lines are congested at critical level. As such, this load can be interpreted as critical because if some line breaks down, the grid fulfils the N-1 rule no longer. Development of VRES increases the number of observations in this critical 'load' significantly in all weeks and scenarios - at least by 20 percent in week 14 in phase-out scenario. At the same time the lowest relative increase in observations of $80 \%$ 'load' in week 14 leads to the highest number of observations among all weeks, due to the fact that winter week 14 has high grid load and the highest number of observations in $80 \%$ 'load' also in the base scenario $(1,529)$. The res-only scenario in week 14 induces the highest number of observations of $80 \%$ 'load' - out of 163,994 combination of 982 lines and 167 hours in week 14 there are 1,858 observations of $80 \%$ 'load', which yields more than 1 percent. This could be interpreted as if almost 10 lines of 982 would be at the limit of their capacity 
constantly during the whole week.

To briefly summarize, this analysis shed light on the changes in the distribution of load in the transmission system from the perspective of each of the mentioned week as a whole. We can conclude that the data are in line with our hypothesis that increase in renewable feed-in causes higher occurrence of observations in higher deciles, including the critical values of $80 \%$, of the grid 'load' and lower occurrence in the lowest deciles. This pattern holds universally across weeks.

The net impact of the nuclear phase-out in the context of Energiewende is isolated as a difference between res-only and phase-out scenarios. Table 4 depicts the difference between res-only and phase-out scenarios in number of observations in each load decile. The percentage change then indicates the relative magnitude of the change related to the base scenario's load.

Tab. 4: Effect of nuclear phase out down on distribution of grid load (phase-out - res-only)

\begin{tabular}{|c|c|c|c|c|c|c|}
\hline \multirow[t]{2}{*}{ Load $[\%]$} & \multicolumn{2}{|r|}{$\begin{array}{l}\text { w14 - high sun } \\
\text { and high wind }\end{array}$} & \multicolumn{2}{|r|}{$\begin{array}{l}\text { w27 - high sun } \\
\text { and low wind }\end{array}$} & \multicolumn{2}{|r|}{$\begin{array}{l}\text { w47 - low sun } \\
\text { and high wind }\end{array}$} \\
\hline & [obs.] & [\% change relative to base] & {$[\mathrm{obs}]$.} & [\% change relative to base] & [obs.] & [\% change relative to base] \\
\hline $0-10$ & -157 & -0.2 & -2529 & -2 & 686 & 0.8 \\
\hline $11-20$ & 175 & 0.6 & 1477 & 6 & -57 & -0.2 \\
\hline $21-30$ & 235 & 1.4 & 599 & 6 & -224 & -1.2 \\
\hline $31-40$ & -65 & -0.6 & 238 & 4 & -181 & -1.7 \\
\hline $41-50$ & 4 & 0.1 & 36 & 1 & -56 & -1.2 \\
\hline $51-60$ & -76 & -2.5 & 160 & 10 & -125 & -4.2 \\
\hline $61-70$ & -59 & -3.7 & -45 & -6 & -8 & -0.5 \\
\hline $71-80$ & -57 & -2.5 & 64 & 5 & -35 & -1.6 \\
\hline 80 & -27 & -1.8 & 30 & 4 & -11 & -0.8 \\
\hline
\end{tabular}

It can be observed that the phase-out itself slightly helps to loosen the 'load' in weeks 14 and 49 as the number of observations increases in the lower range and decreases in the upper range of the spectrum compared with the res-only where German nuclear power stations are in operation. The impact of nuclear phaseout in week 27 is different. We can observe growth in number of observations in all 'load' deciles but the first and seventh decile. Even the critical $80 \%$ 'load' is increased by 4 percent of the base 'load' in phase-out scenario compared to resonly scenario. We should keep in mind that the week 27 has the lowest grid load 
among our representative weeks, which could be one of the reasons the nuclear phase-out has different impact in this week.

The isolated impact of the nuclear phase-out can be summed up in a following manner. If there is a high production from wind power plants or wind and solar power plants together at the same time, the phase-out slightly helps to reduce the load in the grid. However, if there is just a bit of wind production and strong solar feed-in combined with low grid load, the effect partly reverses.

\subsection{Hourly patterns during the week}

We can approach the previous issue also from a different perspective. In this section, we examine the behaviour of the flows over the scope of a particular week and we do not treat the individual hourly observations independently anymore, i.e. we continue to map the flows to particular lines.

In the figures 4-6, we identify congestion patterns throughout time. Each of the figures mirrors one week of our interest. X-axis shows the hours of the day in 24 hour formate. Y-axis shows the number of lines where the flows exceed $50 \%$ or $75 \%$ of the line's capacity in given hour respectively. The number of lines did not exceed 73 in any case, which is about $7.4 \%$ of all lines. One figure depicts all three scenarios in a given week. Gray bars stand for base scenario, yellow and red lines stand for phase-out and black and green lines stand for res-only scenario. This allows to compare visually all relevant combinations of outputs - not only between weeks but also between scenarios.

The general result suggests that the occurrence of high loads follows similar trend as the amount of renewable feed-in (compare to figures 1-3). Also, as the VRES installed capacity grows, number of lines with loads higher than both 50 and $75 \%$ rises as well. More specifically, in the week 14/27/49 there are just $30 / 25 / 21$ hours in the res-only scenario and 35/18/21 hours in the phase-out scenario, where the number of lines is below the baseline case respectively. Another noteworthy observation is that behaviour of the flows in both development sce- 
Fig. 4: No. of lines with loads higher than $50 \%$ during week 14 high sun and wind

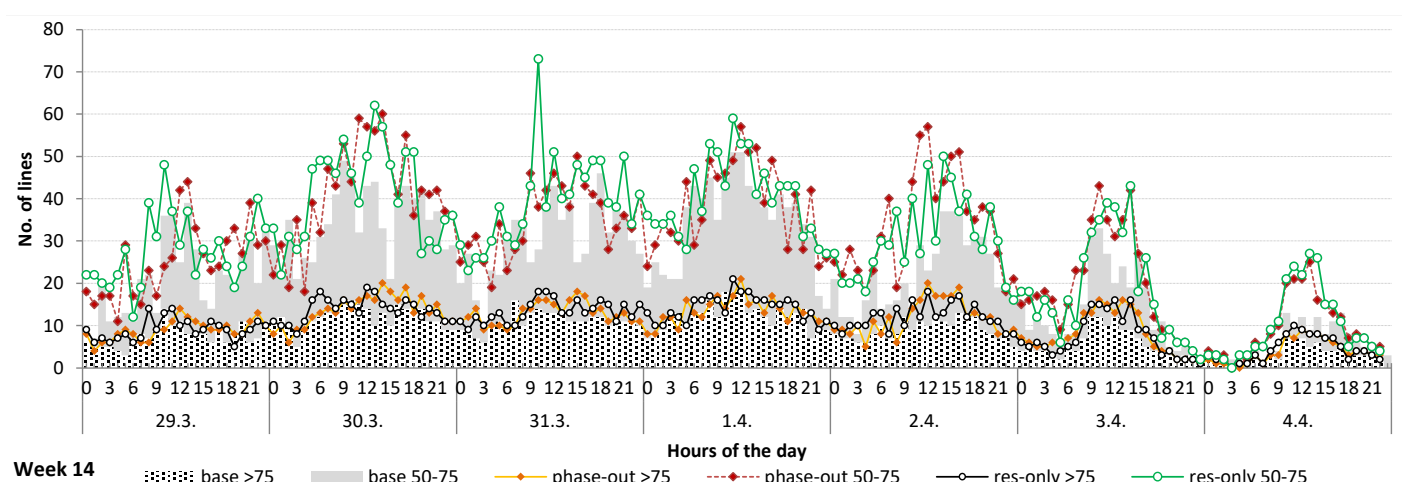

Fig. 5: No. of lines with loads higher than $50 \%$ during week 27 high sun and low wind

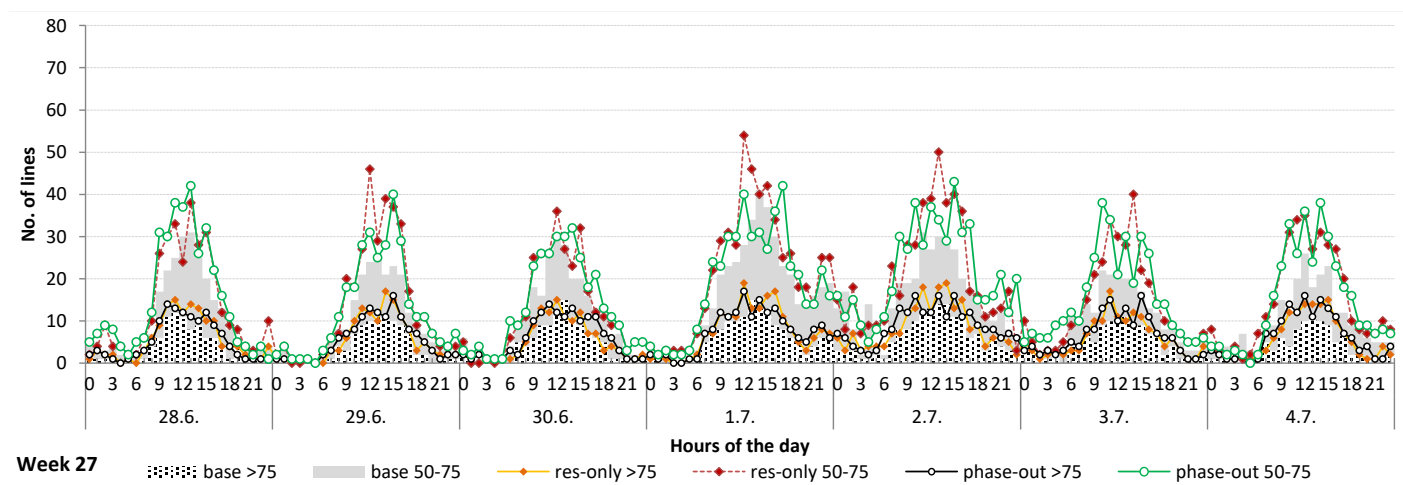

Fig. 6: No. of lines with loads higher than $50 \%$ during week 49 low sun and high wind

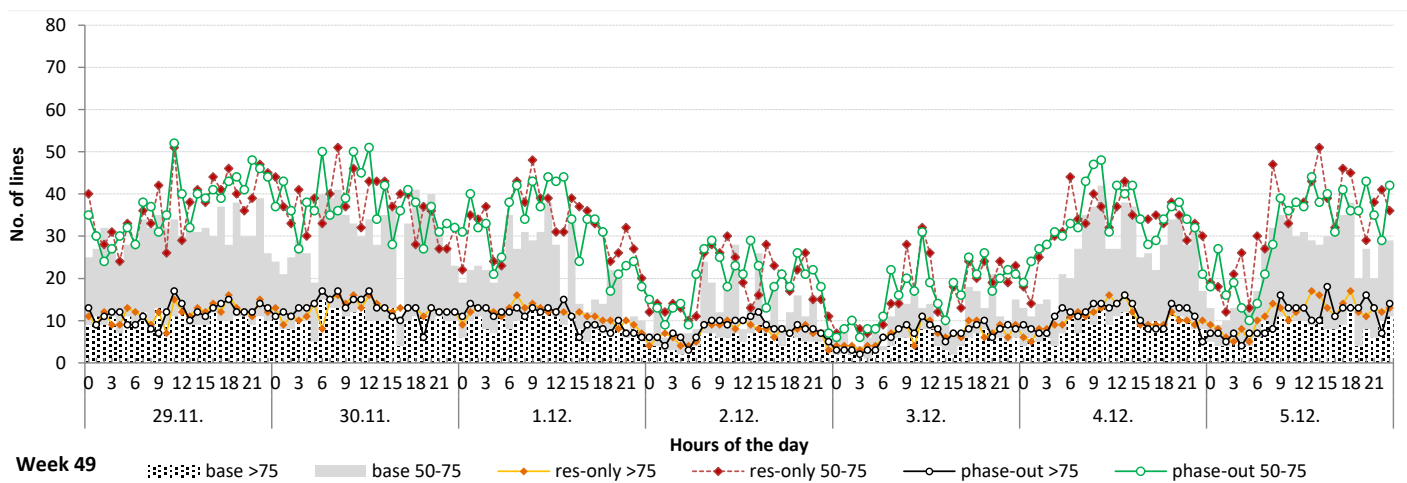

Source: Authors 
narios res-only and phase-out follows very similar trend over time. Nevertheless, there is different dynamics indicating differences in volatility of flows between scenarios. It is also clear that the number of congested lines (load above 75\%) fluctuates less than the number of upper-middle loads in the range of $50-75 \%$. Statements about the magnitude and significance of variances in particular cases would require separate analysis though.

\subsection{Geographical occurrence of highly loaded transmission lines}

The load is not distributed equally across regions as shown in figures 7-9, where a number of transmission lines during the given week is depicted. We include the lines that evince systematic load over $50 \%$ and where also critical events occur frequently. Such lines are concentrated mainly in the centres of wind generation, on the pathway from north of Germany to Austria and in Austria where water pump storage plants are located. This supports our concern about the insufficient pace of new line construction, as stated in the introductory section.

The distribution of load reflects not only the wind and solar generation but also the overall grid load. In the week 27 with the lowest load there are 15 regions with highly-loaded lines in at least one scenario (1 in Poland, 10 in Germany and 4 in Austria), but there are 25 and 29 regions in week 14 and 49, respectively. The highest grid load combined with high wind and low solar power generation in week 49 involves congestions in at least one scenario in all regions in the north of Germany and Poland, regions in Germany on the pathway to Austria and 5 regions in Austria as depicted in figure 9. The high solar and wind feed-in in week 14 involves congestions in at least one scenario in fewer regions than in week 49 only in one region in Poland, in 18 regions in Germany and 6 regions in Austria. The number of congested lines remains the same or increases in almost all regions in both res-only and phase-out scenarios. Just one line (in one German region) in week 14 and three lines (in one German and two Austrian regions) in week 27 are less loaded in the res-ony scenario than in base. The res-ony scenario induces 
critical load on 20, 6 and 17 transmission lines more than in base scenario in weeek 14, 27 and 17, respectively. The phase-out scenario induces critical load on 16, 10 and 16 transmission lines more than in base scenarion in week 14, 27 and 17 , respectively.

\subsection{Policy implications}

We thus identified regions that authorities responsible for the stability of the grid should pay attention to. All scenarios identify roughly the same regions as problematic - from north of Germany to Austria and Austrian regions - only the number of lines changes. The credibility of our results is supported by the fact that regions identified by our model do follow a general pattern of the Ten Year Network Development Plan, as published by (ENTSOE 2017).

In the context of the problematic regions identified above, the table 5 gives an overview of the occurrences of extra high load on the border profiles. The figures represent average values over the lines on the particular profile. Such a presentation of results is chosen due to mutual comparability of the profiles. Extra high load is a value of the load if it lies between $75 \%$ and $80 \%$ of the line's capacity within a particular hour. Loads higher than $80 \%$ do not occur in the model (restriction of the model) as such values would violate the "N-1" security criterion.

The highest values of average extreme load per each line of the border profile occur especially in the centre of the German wind production - in the control area of 50 Hertz. The highest value of the average 23.5 hours of the extreme load over each interconnector between Poland and Germany illustrates the seriousness of the situation on that border and the reason why Poland installed phase-shift transformers in the Mikulova-Neuerbau substation (ACER 2016). Another profiles with extreme load include the profiles within Germany (50 Hertz - TenneT; Amprion - TenneT), but the frequency of extreme loading there is low.

The German-Austria cross-border profile is subject to the largest congestion 
Fig. 7: Regions with most congested lines in the week 14

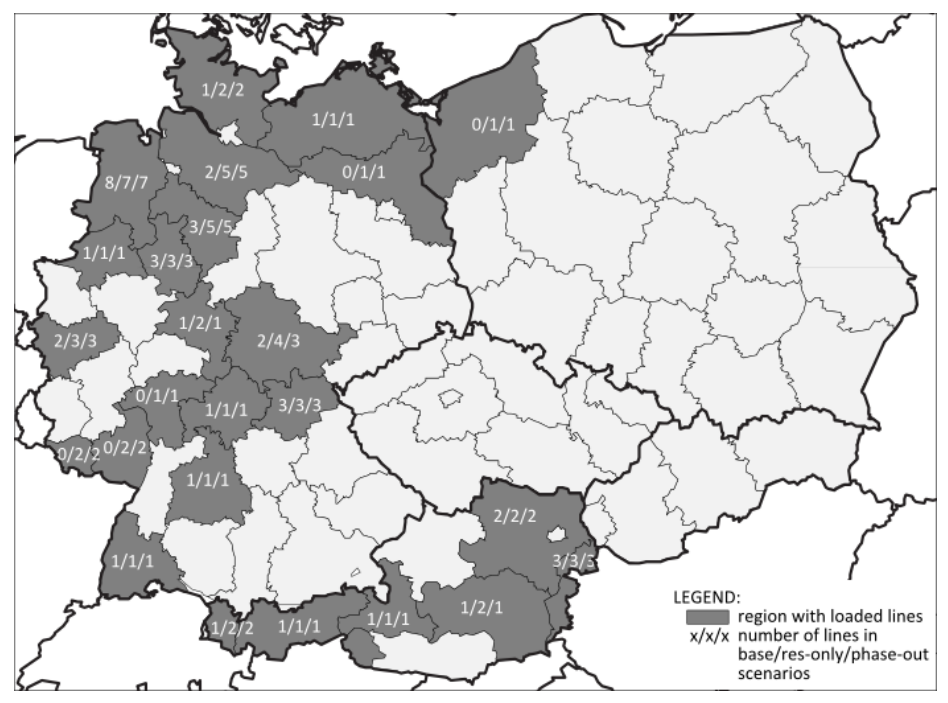

Fig. 8: Regions with most congested lines in the week 27

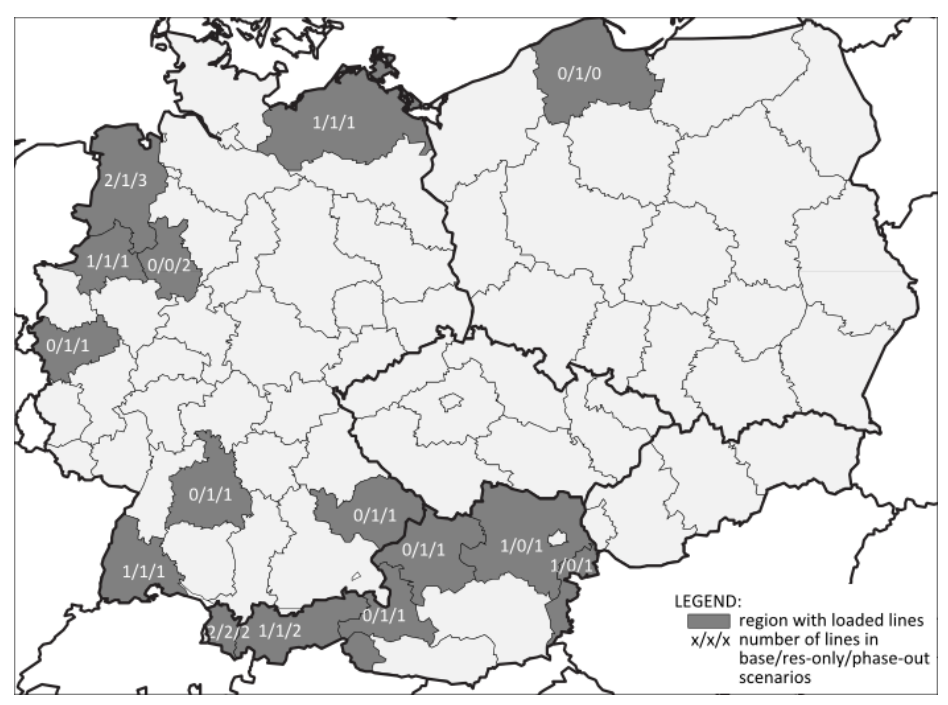

Fig. 9: Regions with most congested lines in the week 49

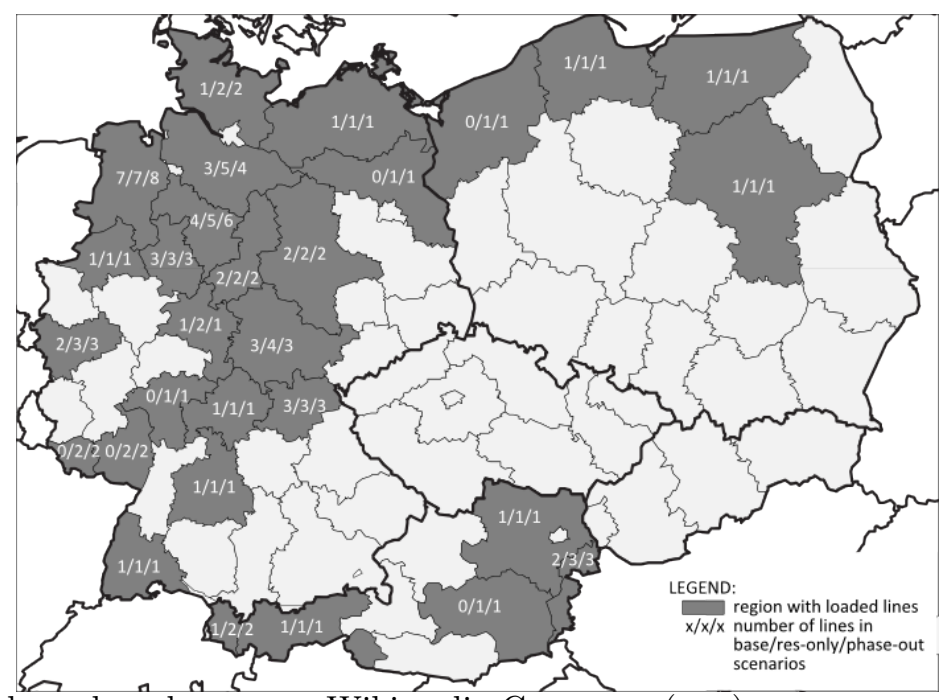

Source: Authors, based on maps Wikimedia 2 (qmmons (n.a.) 
Tab. 5: Extreme load (75-80\%), average weekly hours of extreme load per cross-border line by profile

\begin{tabular}{|c|c|c|c|c|c|c|c|c|c|}
\hline & \multicolumn{3}{|c|}{ high sun. high wind (w14) } & \multicolumn{3}{|c|}{ high sun. low wind (w27) } & \multicolumn{3}{|c|}{ low sun. high wind (w49) } \\
\hline & base & res-only & phase-out & base & res-only & phase-out & base & res-only & phase-out \\
\hline 50Hertz-PSE & 6.50 & 23.50 & 20.00 & 0 & 1.50 & 2.50 & 8.50 & 18.50 & 24.50 \\
\hline 50Hertz-Tennet & 1.00 & 3.13 & 3.13 & 0 & 0 & 0 & 1.75 & 4.88 & 4.00 \\
\hline Amprion-APG & 0 & 0 & 0 & 0 & 0 & 0 & 0 & 0 & 0 \\
\hline Amprion-Tennet & 2.70 & 5.40 & 5.60 & 0.20 & 0.70 & 0.20 & 2.00 & 2.90 & 2.40 \\
\hline Amprion-TransnetBW & 0 & 0 & 0 & 0 & 0 & 0 & 0 & 0 & 0 \\
\hline APG-Tennet & 0.14 & 2.57 & 2.43 & 3.86 & 8.86 & 11.71 & 0 & 0 & 0 \\
\hline APG-TransnetBW & 0 & 0 & 0 & 0 & 0 & 0 & 0 & 0 & 0 \\
\hline CEPS-50Hertz & 0 & 0 & 0 & 0 & 0 & 0 & 0 & 0 & 0 \\
\hline CEPS-APG & 0 & 0 & 0 & 0 & 0 & 0 & 0 & 0 & 0 \\
\hline CEPS-PSE & 0 & 0.25 & 0 & 0 & 0 & 0 & 0 & 0 & 0 \\
\hline CEPS-SEPS & 0 & 0 & 0 & 0 & 0 & 0 & 0 & 0 & 0 \\
\hline CEPS-Tennet & 0 & 0 & 0 & 0 & 0 & 0 & 0 & 0 & 0 \\
\hline PSE-SEPS & 0 & 0 & 0 & 0 & 0 & 0 & 0 & 0 & 0 \\
\hline Tennet-TransnetBW & 0 & 0 & 0 & 0 & 0 & 0 & 0 & 0 & 0 \\
\hline
\end{tabular}

if solar production is high and wind production is low. In particular, this profile exhibits congestion which is disproportionately higher that on the other profiles where it almost does not occur at all. It can be deduced that since the existence of German-Austrian bidding zone allows unlimited electricity trading between Germany and Austria, the market and regulatory framework does not create any incentives to limit the congestion at German-Austrian cross-borders profiles and the connected transmission lines. The results indicate that a profound effort should be dedicated to the development of transmission lines from the north to the south of Germany and to the construction cross-border interconnections. On the other hand, the example of German-Austrian bidding zone shows, that also the regulatory framework matters. One part of the solution could therefore be to change the regulatory framework in such a way that it would bring undistorted price signals to all energy market participants, from the producers to the consumers, as proposed in the Energy Winter Package (European Commission 2017). 


\section{Conclusion}

This paper provides an analysis of the impacts of two major developments in the Central European energy sector - the wind and solar power generation and nuclear phase-out in Germany - on the transmission lines in the region. The reference scenario base and two policy scenarios res-only and phase-out are created to analyse the impacts of the Energiewende as a whole and the net impacts of nuclear phase-out, respectively. The base scenario reflects the year 2015. Scenario res-only reflects the development of German renewables' production according to the Energiewende targets in 2025 and the phase-out scenario adds the nuclear phase-out too. The non-linear optimization model ELMOD is applied to analyse these impacts during three representative weeks in hourly resolution.

The analysis examining the changes in the distribution of load in the transmission system from the perspective of each of the mentioned week as a whole gives us the following conclusion: The data are in line with our hypothesis that increases in renewable feed-in cause higher occurrence of observations in higher load deciles, including the critical values of $80 \%$, of the grid 'load' and lower occurrence in the lowest deciles. This pattern holds universally across weeks.

Under high grid load, the nuclear phase-out has a slightly positive impact on the transmission lines load and congestion. On the other hand, if there is just a bit of wind production and strong solar feed-in combined with low grid load, the effect partly reverses. This supports our expectation that nuclear power is poorly compatible with high shares of renewables.

Our results confirm that increase of German wind and solar electricity generation increase the congestion not only in Germany but also in Austria and Poland. Although the solar power generation is less predictable than wind generation, the results indicate that the increased high solar feed-in has less detrimental impacts on the transmission grid than high wind feed-in. This is given by two circumstances. First, the solar power plants are located closer to the power demand and are not so concentrated in only a few regions in the north of Germany as 
the wind power plants and second, high solar feed-in occurs in summer when the grid load is lower. Wind feed-in is more correlated with network load than solar feed-in. This helps to satisfy the electricity demand by renewable sources, but due to the fact the wind generation is concentrated in the north of Germany, it induces higher load of transmission lines and even congestions. High wind feed-in burdens the transmission lines in the north-south direction in Germany. This implies that any delay in transmission grid development plan (Bundesnetzagentur 2017) could involve a serious problem in the grid.

\section{Appendix A. Mathematical formulation}

The objective function of the model (for more details see Leuthold et al. (2012)) maximizes social welfare

$$
\max _{g_{n c t}, q_{n t}}\left\{w=\sum_{n, t}\left(\int_{0}^{q_{n t}} \pi_{n t}\left(q_{n t}\right) d q_{n t}-\sum_{c} g_{n c t} M_{n c}\right)\right\}
$$

where $\pi_{n t}$ is linear inverse demand function with non-negative intercept $A_{n t}$ and negative slope coefficient $D_{n t}$ :

$$
\pi_{n t}\left(q_{n t}\right)=A_{n t}+D_{n t} q_{n t}
$$

The coefficient $M_{n c}$ is time-invariant marginal cost of generation for each individual power plant unit $c$ at node $n$ determined based on the model data.

In this paper the ELMOD runs as cost minimization model as the reference demand values at each node $q_{n t}$ are fixed.

When solving Eq. 1 several energy balance constraints have to be accounted for. The nodal balance constraint (sum of all inflows equals sum of all outflows) has to be true for any node at any point in time:

$$
\sum_{c} g_{n c t}+G_{n t}^{\text {wind }}+G_{n t}^{\text {solar }}+P S P_{n t}^{\text {out }}-P S P_{n t}^{\text {in }}+\sum_{n n} \theta_{n n, t} B_{n, n n}-q_{n t}=0 \quad \forall n, t .
$$


Electricity inflows include total generation from conventional power plants $\sum_{c} g_{n c t}$, wind generation $G_{n t}^{\text {wind }}$, solar generation $G_{n t}^{\text {solar }}$ and pumped-power plant release $P S P_{n t}^{\text {out }}$. Electricity outflows include pumping of pumped-storage power plants $P S P_{n t}^{i n}$ and consumption $q_{n t}$. The term $\sum_{n n} \theta_{n n, t} B_{n, n n}$ is specific to the technical characteristics of electricity and is responsible for balancing the remaining small deviations of the constraint.

The electricity production from power plant is bounded by the installed capacity of given production unit and cannot exceed this value:

$$
g_{n c t} \leq G_{c t}^{\max } \quad \forall n, c, t
$$

Electricity flows are modeled by

$$
p_{l t}=\sum_{n} H_{l n} \theta_{n t} \quad \forall l, t
$$

Inequality (6) takes into account the capacity limits of individual transmission lines and restricts the modelled flow to respect these upper and lower bounds respectively.

$$
\left|p_{l t}\right| \leq \bar{P}_{l} \quad \forall l, t
$$

The equation (7) sets the voltage angle of an arbitrary node, called slack node, to be zero which is important because uniqueness of solution of the system is thus guaranteed. Due to the setting of the voltage angle of one variable, all other angle values are relative to this specific one.

$$
\begin{gathered}
\theta_{n^{\prime} t}=0 \quad \forall n, t . \\
P_{j k}=B_{j k} \theta_{j k} .
\end{gathered}
$$

Last steps in obtaining desired result in form of particular line flow incorporate the identification of nodes $n, n n$ and mapping to the lines. For this purpose, 
Leuthold et al. (2012) uses a special matrix, incidence matrix $I_{l n}$, which is defined followingly:

$$
I_{l n}= \begin{cases}1 & \text { if } n=j \\ -1 & \text { if } n=k \\ 0 & \text { else. }\end{cases}
$$

With the help of series line susceptance $B_{l n}$, final line power flow (5) can be obtained:

$$
\begin{gathered}
H_{l n}=B_{l n} I_{l n} \\
p_{l t}=\sum_{n} H_{l n} \theta_{n t} .
\end{gathered}
$$

Referring to the previous text on net input, technical description is added. Net input variable is determined by network susceptance matrix and voltage angles $\nu_{n t}=\sum_{n n} B_{n, n n} \theta_{n n, t}$. Mathematical derivation of the first parameter, the susceptance matrix $B_{n, n n}$, is based on above mentioned flow definitions (Leuthold et al. 2012).

$$
B_{n, n n}=\sum_{l} I_{l n} H_{l n}
$$

Sets and indices:

$L$

$N$

C

$T$

$l \in L$

$n, n n \in N$

$n^{\prime} \in N$

$c \in C$

$t \in T$ set of all lines

set of all nodes

set of all conventional plants

set of all time periods

line within the network

nodes within the network

slack node(s) within the network

conventional power plant unit

time periods 
Parameters:

$G_{n t}^{\text {wind }}$

wind input at node $n$ in time $t$

$G_{n t}^{\text {solar }}$

PSP $P_{\text {nt }}^{\text {out }}$

solar input at node $n$ in time $t$

$P S P_{n t}^{i n}$

pump storage plant release at node $n$ in time $t$

$G_{c t}^{\max }$

$\bar{P}_{l t}$

$H_{l n}$

$B_{n, n n}$

$A_{n t}$

pump storage loading at node $n$ in time $t$

$D_{n t}$

$M_{n c}$

maximal generation of generation unit $c$ in time $t$

maximal available capacity limit of line $l$ in time $t$

network transfer matrix

network susceptance matrix

intercept coefficient at node $n$ in time $t$

slope coefficient at node $n$ in time $t$

marginal cost coefficient of power plant unit $c$ at node $n$

Variables:

$w$

welfare function

$\pi_{n t}\left(q_{n t}\right)$

inverse demand function at node $n$ in time $t$

$m_{n c t}\left(g_{n c t}\right)$

marginal cost of generation of plant $c$ at node $n$ in time $t$

$g_{n c t}$ generation of generation unit $c$ at node $n$ in time $t$

$q_{n t}$

$\nu_{n t}$

demand at node $n$ in time $t$

$p_{l t}$

net input to node $n$ in time $t$

$\theta_{n t}, \theta_{n n, t}, \theta_{n^{\prime} t}$

power flow over line $l$ in time $t$

flow angle at node $n$ in time $t$

\section{References}

ACER (2016): "First four phase shift transformers at German-Polish border in operation." http://www.50hertz.com/en/News/Detail/id/1533/ first-four-phase-shift-transformers-at-german-polish-border-in-operation.

[Online; accessed 09-August-2017].

AGEB (2015): "Bruttostromerzeugung in Deutschland ab 1990 nach Energieträgern."

Technical report, AG Energiebilanzen, e.V.

APG (2015): "Network development plan 2015." https://www.apg.at/ /media/ A74BB5124C2545EAB85F15BF946BA036.pdf. [Online; accessed 22-April-2016].

Blest, M., A. Das, U. Fahl, \& U. Remme (2007): "Role of energy efficiency standards 
in reducing CO2 emissions in Germany: An assessment with TIMES." Energy Policy 35(2): pp. $772-785$.

BMWi (2015a): An electricity market for Germany's energy transition - White Paper by the Federal Ministry for Economic Affairs and Energy. Budnesministerium für Wirtschaft und Energie.

BMWi (2015b): Die Energie der Zukunft: Vierter Monitoringbericht zur Energiewende. Budnesministerium für Wirtschaft und Energie.

BMWI (2015c): "Um diese Projekte geht es beim Netzausbau." https: //www. bmwi-energiewende.de/EWD/Redaktion/Newsletter/2015/9/Meldung/ infografik-netzausbauprojekte.html. [Online; accessed 22-April-2016].

Bundesnetzagentur (2015): "Why is the grid expansion necessary." http://www . netzausbau.de/EN/background/why/en.html. [Online; accessed 22-April-2016].

BundesnetZaGentur (2017): "Leitungsvorhaben." http://www.netzausbau.de/ leitungsvorhaben/de.html. [Online; accessed 13-Aug-2017].

Burstedde, B. (2012): "From nodal to zonal pricing: A bottom-up approach to the second-best." In "9th International Conference on the European Energy Market (EEM)," pp. 1-8. IEEE.

ČEPS (2015a): "Construction of PSTs." https://www.ceps.cz/CZE/Media/ Ke-stazeni/Documents/Publikace/Stavba\%20PST\%20transformator\%C5\%AF.pdf. [Online; accessed 3-February-2017].

ČEPS (2015b): "Development Plan for the Transmission System of the Czech Republic 2015 - 2024." http://www.ceps.cz/ENG/Cinnosti/Technicka-infrastruktura/ Documents/Development\%20Plan\%202015-2024.pdf. [Online; accessed 22-April2016].

ČEPS (2017): "The transmission system is more stable thanks to the regulating transformers." http://www.ceps.cz/ENG/Media/Tiskove-zpravy/Pages/ P\%C5\%99enosov\%C3\%A1-soustava-je-stabiln $\%$ C4\%9Bj\%C5\%A1\%C3\%AD-d\%C3\% ADky-regula $\%$ C4\%8Dn\%C3\%ADm-transform\%C3\%A1tor\%C5\%AFm.aspx. [Online; accessed 13-August-2017]. 
Cludius, J., H. Hermann, F. C. Matthes, \& V. Graichen (2014): "The merit order effect of wind and photovoltaic electricity generation in Germany 2008-2016: Estimation and distributional implications." Energy Economics 44: pp. 302-313.

Dietrich, K., F. Leuthold, \& H. Weigt (2010): "Will the market get it right? The placing of new power plants in Germany." Zeitschrift für Energiewirtschaft 34(4): pp. $255-265$.

Egerer, J., C. Gerbaulet, R. Ihlenburg, F. Kunz, B. Reinhard, C. von Hirschhausen, A. Weber, \& J. Weibezahn (2014): "Electricity sector data for policy-relevant modeling: Data documentation and applications to the German and European electricity markets." Technical report, Data Documentation, DIW.

ENTSOE (2016): "ENTSOE Transpareny Platform." https://transparency. entsoe.eu/. [Online; accessed 22-April-2016].

ENTSOE (2017): "Ten Year Network Development Pland." https: //www.entsoe.eu/major-projects/ten-year-network-development-plan/ ten\%20year\%20network\%20development\%20plan\%202016/Pages/default. aspx. [Online; accessed 06-February-2017].

Eser, P., A. Singh, N. Chokani, \& R. S. Abhari (2015): "High resolution simulations of increased renewable penetration on central European transmission grid." In "Power \& Energy Society General Meeting, 2015 IEEE," pp. 1-5. IEEE.

European Commission (2017): "Proposal for a regulation of the European Parliament and ot the Council on the internal market for electricity. $\operatorname{COM}(2016) 861$ final/2."

European Commission, DG Energy (2016a): "EU Crude Oil Imports and Supply Cost." https://ec.europa.eu/energy/en/statistics/eu-crude-oil-imports. [Online; accessed 22-April-2016].

European Commission, DG Energy (2016b): "Quarterly Report on European Electricity Markets." https://ec.europa.eu/energy/en/statistics/ market-analysis. [Online; accessed 22-April-2016].

European Commission, DG Energy (2016c): "Quarterly Report on European Gas Markets." https://ec.europa.eu/energy/en/statistics/market-analysis. [Online; accessed 22-April-2016]. 
Feix, O., R. Obermann, M. Hermann, \& S. Zeltner (2015): Netzentwicklungsplan Strom 2015, Version 2015. Entwurf der Übertragungnetzbetreiber. CB. e Clausecker, Bingel AG, Germany.

Fischer, W., J.-F. Hake, W. Kuckshinrichs, T. Schröder, \& S. Venghaus (2016): "German energy policy and the way to sustainability: Five controversial issues in the debate on the "Energiewende"." Energy 115: pp. 1580-1591.

Flechter, J. \& S. Bolay (2015): "Faktenpapier Ausbau der Stromnetze." Technical report, DIHK.

Fürsch, M., S. Hagspiel, C. Jägemann, S. Nagl, D. Lindenberger, \& E. Tröster (2013): "The role of grid extensions in a cost-efficient transformation of the European electricity system until 2050." Applied Energy 104: pp. 642-652.

HavlíčKová, K., J. Weger, \& J. Knápek (2011): "Modelling of biomass prices for bio-energy market in the Czech Republic." Simulation Modelling Practice and Theory 19(9): pp. 1946-1956.

Janda, K., Š. KrŠKa, J. PrŮŠa et al. (2014): "Czech Photovoltaic Energy: Model Estimation of The Costs of its Support." Politická ekonomie 2014(3): pp. 323-346.

JANDA, K., J. MÁLEK, \& L. REČKA (2017): "Influence of renewable energy sources on transmission networks in central europe." Energy Policy 108: pp. 524-537.

Keles, D., D. Möst, \& W. Fichtner (2011): "The development of the German energy market until 2030 - a critical survey of selected scenarios." Energy Policy 39(2): pp. 812-825.

Ketterer, J. C. (2014): "The impact of wind power generation on the electricity price in Germany." Energy Economics 44: pp. 270-280.

Kocot, H., R. Korab, W. Lubicki, M. Przygrodzki, G. Tomasik, \& K. Zmuda (2013): "Improving the cross-border transmission capacity of Polish power system by using phase shifting transformers." In "CIGRE 7th Southern Africa Regional Conference," pp. 7-11.

Korab, R. \& R. OwCZAREK (2016): "Impact of phase shifting transformers on crossborder power flows in the Central and Eastern Europe region." Bulletin of the Polish Academy of Sciences Technical Sciences 64(1): pp. 127-133. 
KunZ, F. (2013): "Improving congestion management: how to facilitate the integration of renewable generation in Germany." The Energy Journal 34(4): pp. 55-79.

Kunz, F. \& A. Zerrahn (2015): "Benefits of coordinating congestion management in electricity transmission networks: Theory and application to Germany." Utilities Policy 37: pp. 34-45.

Kunz, F. \& A. Zerrahn (2016): "Coordinating Cross-Country Congestion Management: Evidence from Central Europe.” Energy Journal 37: pp. 81-100.

Leuthold, F., H. Weigt, \& C. v. Hirschhausen (2008): "ELMOD - a model of the European electricity market." Technical report, Electricity Markets Working Paper WPEM-00, Dresden University of Technology, Chair for Energy Economics and Public Sector Management.

Leuthold, F. U. (2009): Economic Engineering Modeling of Liberalized Electricity Markets: Approaches, Algorithms, and Applications in a European Context. Ph.D. thesis, Technische Universität Dresden, Fakultät der Wirtschaftwissenschaften.

Leuthold, F. U., H. Weigt, \& C. Von Hirschhausen (2012): "A large-scale spatial optimization model of the European electricity market." Networks and spatial economics 12(1): pp. 75-107.

Majchrzak, H., G. Tomasik, D. Owczarek, \& K. Purchąa (2013): "Crossborder unplanned flows in European power system as obstacle towards Integrated Electricity Market." In "CIGRE 7th Southern Africa Regional Conference," pp. 7-11.

Meyer, T. \& J. Luther (2004): "On the correlation of electricity spot market prices and photovoltaic electricity generation." Energy Conversion and Management 45(17): pp. 2639-2644.

Mulder, M. \& B. Scholtens (2016): "A plant-level analysis of the spill-over effects of the German Energiewende." Appl. Energy 183: pp. 1259-1271.

Neuhoff, K., J. Barquin, J. W. Bialek, R. Boyd, C. J. Dent, F. Echavarren, T. Grau, C. Von Hirschhausen, B. F. Hobbs, F. Kunz et al. (2013): "Renewable electric energy integration: quantifying the value of design of markets for international transmission capacity." Energy Economics 40: pp. 760-772.

Neuhoff, K., J. Barquin, M. G. Boots, A. Ehrenmann, B. F. Hobbs, F. A. RiJKeRs, \& M. VAzQUEz (2005): "Network-constrained Cournot models of liberalized 
electricity markets: the devil is in the details." Energy Economics 27(3): pp. 495525.

Overbye, T. J., X. Cheng, \& Y. Sun (2004): "A comparison of the AC and DC power flow models for LMP calculations." In "System Sciences, 2004. Proceedings of the 37th Annual Hawaii International Conference on," pp. 9-pp. IEEE.

PrơšA, J., A. KlimeŠovÁ, \& K. Janda (2013): "Consumer loss in Czech photovoltaic power plants in 2010-2011." Energy Policy 63: pp. 747-755.

PSE (2015): "Development plan for meeting the current and future electricity demand for 2016-2025." http://www.pse.pl/uploads/kontener/Development_Plan_for_ meeting_the_current_and_future_electricity_demand_for_2016-2025.pdf.

[Online; accessed 22-April-2016].

Purchala, K., L. Meeus, D. Van Dommelen, \& R. Belmans (2005): "Usefulness of DC power flow for active power flow analysis." In "Power Engineering Society General Meeting, 2005. IEEE," pp. 454-459. IEEE.

RAPP, H. (2012): Energieversorgung im Wandel: Hoffnungen und Fakten zur Energiewende. Pro Business.

REČKA, L. \& M. ŠČASNÝ (2013): "Environmental regulation impacts on the Czech power system by the dynamic linear optimisation model MESSAGE." Politická ekonomie 2013(2): pp. 248-273.

REČKA, L. \& M. ŠČASNÝ (2016): "Impacts of carbon pricing, brown coal availability and gas cost on Czech energy system up to 2050." Energy 108: pp. 19-33.

ŠČasný, M., V. Píša, H. Pollit, \& U. Chewpreecha (2009): “Analyzing Macroeconomic Effects of Environmental Taxation in the Czech Republic with the Econometric E3ME Model." Czech Journal of Economics and Finance (Finance a uver) 59(5): pp. $460-491$.

Schaber, K., F. Steinke, \& T. Hamacher (2012a): "Transmission grid extensions for the integration of variable renewable energies in Europe: Who benefits where?" Energy Policy 43: pp. 123-135.

Schaber, K., F. Steinke, P. Mühlich, \& T. Hamacher (2012b): "Parametric study of variable renewable energy integration in Europe: Advantages and costs of transmission grid extensions." Energy Policy 42: pp. 498-508. 
Schroeder, A., P.-Y. Oei, A. Sander, L. Hankel, \& L. C. Laurisch (2013): "The integration of renewable energies into the German transmission grid - A scenario comparison." Energy Policy 61: pp. 140-150.

Schubert, D. K. J., T. Meyer, \& D. Möst (2015a): "Die Transformation des deutschen Energiesystems aus der Perspektive der Bevölkerung." Zeitschrift für Energiewirtschaft 39(1): pp. 49-61.

Schubert, D. K. J., S. Thuss, \& D. Möst (2015b): "Does political and social feasibility matter in energy scenarios?" Energy Research 85 Social Science 7: pp. 43-54.

Schweppe, F. C., M. C. Caramanis, R. D. Tabors, \& R. E. Bohn (1988): Spot pricing of electricity. Springer Science \& Business Media.

Singh, A., T. Frei, N. Chokani, \& R. S. Abhari (2016): "Impact of unplanned power flows in interconnected transmission systems-Case study of Central Eastern European region." Energy Policy 91: pp. 287-303.

Singh, A., D. Willi, N. Chokani, \& R. S. Abhari (2015): "Increasing On-Shore Wind Generated Electricity in Germany's Transmission Grid." Journal of Engineering for Gas Turbines and Power 137(2): p. 021801.

Stigler, H. \& C. Todem (2005): "Optimization of the Austrian electricity sector (Control Zone of VERBUND APG) by nodal pricing." Central European Journal of Operations Research 13(2): p. 105.

Traber, T. \& C. Kemfert (2009): "Impacts of the German support for renewable energy on electricity prices, emissions, and firms." The Energy Journal 30(3): pp. $155-178$.

Weigt, H., T. Jeske, F. Leuthold, \& C. von Hirschhausen (2010): "Take the long way down: Integration of large-scale North Sea wind using HVDC transmission." Energy Policy 38(7): pp. 3164-3173.

Wikimedia Commons (n.a.): "NUTS 2 regions EU-27." https://commons. wikimedia.org/wiki/File:NUTS_2_regions_EU-27.svg.

Winkler, J., A. Gaio, B. Pfluger, \& M. Ragwitz (2016): "Impact of renewables on electricity markets-Do support schemes matter?" Energy Policy 93: pp. 157-167. 